\title{
Assessment of Level of Serum Cardiac Troponin T in Neonates with Respiratory Distress Syndrome
}

\author{
Amr Ismail Abd-El Moez ${ }^{* 1}$, HanaaAbd-Elfattah Mohamed ${ }^{1}$, Azza Ali Khalil ${ }^{1}$, Hanan Samir Ahmed ${ }^{2}$ \\ Departments of ${ }^{1}$ Pediatrics and ${ }^{2}$ Clinical Pathology, Faculty of Medicine, Zagazig University, Sharkia, Egypt \\ *Corresponding author: Amr Ismail Abd-El Moez, E-mail: darkknightrises375@gmail.com
}

\begin{abstract}
Background: One of the most prevalent reasons for admission to neonatal intensive care units (NICUs) is respiratory distress syndrome (RDs). When myocardial cells are damaged, cardiac troponin I (cTnT) is released as a biomarker of myocardial damage, which is very specific and sensitive.

Objective: To determine the level of cTnT in preterm infants who have respiratory distress syndrome as a marker of cardiac dysfunction.

Patients and Methods: This study was carried as a case-control trial on forty preterm infants, 20 patients of respiratory distress syndrome at neonatal intensive care unit as a group I, 20 apparently healthy newborns as a control group. Serum cardiac troponin $\mathrm{T}$ level sample was taken on the 3rd day of delivery.

Results: A statistically significant difference in blood troponin was found between the groups tested, with a negative connection between serum troponin and gestational age, length, and APGAR scores at the first and fifth minutes of life. Respiratory rate and serum troponin were found to have a statistically significant connection. Any one of the echocardiographic measures had a statistically significant positive connection with serum troponin. Serum troponin was able to diagnose respiratory distress syndrome with cutoff $\geq 93.5 \mathrm{ng} / \mathrm{mL}$ with the area under the curve, Positive predictive value: $83.33 \%$ Positive predictive value: $83.33 \%$ Negative predictive value: 100 percent Accuracy: $90 \%$.

Conclusion: Cardiac troponin $\mathrm{T}$ can be used to detect cardiac dysfunction in ill newborns, especially in centers that do not have in-house echocardiography.
\end{abstract}

Keywords: Respiratory Distress Syndrome, Cardiac Troponin T.

\section{INTRODUCTION}

Premature and sick infants are more likely to have a compromised cardiovascular system. Perinatal Asphyxia as well as respiratory distress syndrome are prominent causes of impaired myocardial contractility and decreased cardiac output ${ }^{(\mathbf{1})}$.

Hypotension, which is associated with an increased risk of death and poor neurological sequelae, may be a clinical sign of a diminished cardiovascular reserve. Ischemia and necrosis have been hypothesized to be the cause of this myocardial dysfunction or stunning ${ }^{(2)}$.

Cardiac biomarkers are increasingly being used as measures of myocardial strain in clinical trials. In addition, they may be utilized to help guide treatment and enhance outcomes. As diagnostic and therapeutic instruments in the case of neonatal disease complicated by circulatory compromise, they have a great potential role in helping the management of these conditions ${ }^{(3)}$.

Creatine kinase isoforms have previously been employed as biochemical indicators of cardiac damage in newborns. Since gestational age, gender, mode of delivery, and birth weight all affect creatine kinase, these markers have largely been disregarded ${ }^{(1)}$.

There is a sensitive and specific marker for ischemia myocardial cell injury in both the adult and juvenile populations of cardiac troponin $\mathrm{T}$ ( $\mathrm{cTnT}$ ) detection in the blood $^{(4)}$.

Various muscle types have distinct versions of troponin T, C, and I. Myocardial necrosis can now be diagnosed using cardiac troponins $\mathrm{T}$ and $\mathrm{I}$, which have long been recognized as the best biochemical indicators. As soon as two hours after a full-thickness myocardial infarction, concentrations can stay elevated for two weeks ${ }^{(5)}$.

Numerous healthy newborns have cardiac troponin $\mathrm{T}$ detected in their blood, but no link has been identified between the troponin and critical clinical or biological factors. Concentrations in sick newborns are far more pronounced than in healthy neonates. Using a regression model, the fluctuation in cardiac troponin $\mathrm{T}$ concentration was found to be a significant predictor of oxygen consumption or inotropic support. For neonates and those with cardiorespiratory issues, cardiac troponin $\mathrm{T}$ may be a helpful marker ${ }^{(\mathbf{1})}$.

This study aimed at testing for cardiac failure in preterm babies with respiratory distress syndrome by measuring the amount of serum cTnT.

\section{PATIENTS AND METHODS}

In neonatal intensive care, this case-control trial was carried out, at Zagazig University Hospitals, between January 2019 to January 2021.

Ethical consent:

Approval of the study was obtained from the Zagazig University academic and ethical committee (ZU-IRB\#6250). Every patient signed informed written consent for the acceptance of the operation. This work has been carried out following The Code of Ethics of the World Medical Association 


\section{(Declaration of Helsinki) for studies involving humans.}

Inclusion criteria: Preterm infant suspected to have RDS, and respiratory distress syndrome (on supportive oxygen and ventilation oxygen support).

Exclusion criteria: Infant's age above one month, congenital heart disease. (Congenital anomalies), an infant with metabolic diseases, and refusal of infant's parents.

This study was conducted on forty preterm infants divided into two groups:

- Group (I) (case group): respiratory distress syndrome has been diagnosed in 20 babies referred to the neonatal intensive care unit at the Zagaig University Hospital. The cases group included 8 males (40\%) and 12 females $(60 \%)$. Birth weights ranged from 0.850 to $2 \mathrm{~kg}$, while gestational ages ranged from 28-34 weeks with a mean of $31.2 \pm 0.89$ weeks. They had less than 90 percent oxygen saturation and an Apgar score of fewer than 7.

- Group II (the control group) consisted of 20 neonates who appeared to be in good health. This group was made up entirely of females: 9 of the participants were male and 11 were female (45 percent). Their gestational ages ranged from 36-38 weeks with a mean of $36.9 \pm 0.72$ weeks, and their birth weights ranged from $2-4 \mathrm{~kg}$ with a mean of $2.08 \pm 0.14 \mathrm{~kg}$.

The studied patients went through the following:

1. Full history taking.

2. Clinical examination: Especially looking for, gestational age, Difficulty in breathing, low activity, poor suckling, -ve Moro reflex, flaccidity, skin color, respiratory rates, and its grades.

\section{Laboratory investigations include:}

- Complete blood count, performed on Sysmex XN-2000 cell counter supplied by (Sysmex, Japan).

- C reactive protein by Cobase 6000 (Roche, Germany).

- Liver function tests (Albumin, Total protein, ALT, AST, T.bilirubin, D.bilirubin) using Cobas 8000 (Roche, Germany).

- Kidney function tests: using Cobas 8000 (Roche, Germany)

- ABG done by:(RUMI BG) (Argantina)

- Sepsis screen: CBC, CRP, Blood Culture (6). Special investigations: (serum cardiac troponin $T$ level): Using Cobas 8000 (Roche, Germany), and Blood sample: on 3rd day after birth. A blood sample was then serum obtained at room temperature, the sample was coagulated for 10 to 20 minutes, centrifuged for 20 minutes at 2000-3000 rpm, and any precipitation was re-centrifuged.

Radiological investigations: ECHO: the most accurate investigation in detecting any cardiac dysfunction and chest X-RAY: help in detecting any lung problems like pneumonia and diagnosing RDS grades.

\section{Statistical analysis:}

For statistical analysis, SPSS version 25 was employed. To evaluate statistical significance, two study group averages were compared using the Student T-test. Correlation data were tested using Pearson's correlation coefficient (r). To measure accuracy, terminology like sensitivity and specificity were used to describe it, as well as negative and positive predictive values, and overall accuracy. The Mann-Whitney test was used to compare two unrelated samples. Qualitative data were analyzed using Pearson's chi-square (2) test, in cases where the significance level was defined as 0.05 or less.

\section{Results:}

Between the groups, there was no statistically significant difference in gender, age, or family history (Table 1).

Between groups, there was no significant difference in respiratory distress severity or feeding method. When it came to cyanosis, there was a statistically significant difference between the groups. All patients within the case group were cyanotic; $60 \%$ of them had peripheral cyanosis and $40 \%$ had central cyanosis (Table 2).

Serum troponin levels differed statistically between the groups (it was significantly higher among the case group) (Table 3).

Each gestational age, length, and APGAR score at first and fifth minutes had a statistically significant negative connection with serum troponin in the case group. There was a statistically positive correlation between serum troponin and respiratory rate. There was a statistically significant negative connection between serum troponin and APGAR scores at the first minute among the control group. Serum troponin levels correlated statistically well with both gestational age and birth weight in the study's cases, Each of TLC, platelet count, direct bilirubin, serum blood urea nitrogen, ALT, AST, C reactive protein, serum sodium, and serum potassium had a statistically positive connection with serum troponin. Among the control group, there was a statistically significant negative correlation between serum troponin and TLC, platelets, AST, and CRP. There was a statistically positive correlation between serum troponin and each of hemoglobin, serum BUN, ALT, serum sodium, and potassium (Table 4).

All echocardiographic measures had a statistically significant connection with serum troponin in the case group. PWT, IVS, AORTA, Ejection fraction, and fraction shortening all fall under this category (Table 5).

This cutoff for serum troponin was found to have an area under curve 1 of $100 \%$ sensitivity, $100 \%$ specificity, $83 \%$ positive predictive value, 100 percent negative predictive value, and $90 \%$ accuracy in the diagnosis of respiratory distress syndrome in the individuals investigated $(\mathrm{p}<0.001)$ (Table 6). 
Table (1): Comparison of the demographics of the various groups

\begin{tabular}{|c|c|c|c|c|}
\hline \multirow[t]{3}{*}{ Parameter } & \multicolumn{2}{|c|}{ Groups } & \multicolumn{2}{|c|}{ Test } \\
\hline & Case group & Control group & $\chi^{2} / t$ & $\mathbf{p}$ \\
\hline & $\mathrm{N}=20(\%)$ & $\mathrm{N}=20(\%)$ & & \\
\hline $\begin{array}{c}\text { Gender: } \\
\text { Male } \\
\text { Female }\end{array}$ & $\begin{array}{c}8(40) \\
12(60)\end{array}$ & $\begin{array}{l}11(55) \\
9(45)\end{array}$ & 0.902 & 0.342 \\
\hline $\begin{array}{l}\text { Age (day): } \\
\text { mean } \pm \text { SD }\end{array}$ & $2.9 \pm 0.64$ & $3.35 \pm 0.49$ & 3.043 & 0.13 \\
\hline $\begin{array}{l}\text { Order: } \\
\text { First } \\
\text { Second } \\
\text { Third } \\
\text { Fourth } \\
\text { Fifth }\end{array}$ & $\begin{array}{c}2(10) \\
3(15) \\
11(55) \\
2(10) \\
2(10)\end{array}$ & $\begin{array}{c}3(15) \\
6(30) \\
10(50) \\
1(5) \\
0(0)\end{array}$ & 2.679 & 0.102 \\
\hline
\end{tabular}

t Independent sample t-test $\chi 2$ Chi square test, ${ }^{* *} \mathrm{p} \leq 0.001$ is statistically highly significant

Table (2): An analysis based on differences in respiratory distress scores found among the participants

\begin{tabular}{|c|c|c|c|c|}
\hline \multirow[t]{3}{*}{ Parameter } & \multicolumn{2}{|c|}{ Groups } & \multicolumn{2}{|c|}{ Test } \\
\hline & Case group & Control group & $\chi^{2}$ & $\mathbf{p}$ \\
\hline & $\mathrm{N}=20(\%)$ & $\mathrm{N}=20(\%)$ & & \\
\hline $\begin{array}{l}\text { RD grades: } \\
\text { III } \\
\text { IV }\end{array}$ & $\begin{array}{l}12(60) \\
8(40)\end{array}$ & $\begin{array}{c}14(70) \\
0(0)\end{array}$ & 0.44 & 0.507 \\
\hline $\begin{array}{l}\text { Murmur: } \\
\text { Present }\end{array}$ & $20(100)$ & $5(20)$ & & \\
\hline $\begin{array}{c}\text { Cyanosis: } \\
\text { No } \\
\text { Peripheral } \\
\text { Central }\end{array}$ & $\begin{array}{c}0(0) \\
12(60) \\
8(40)\end{array}$ & $\begin{array}{c}7(35) \\
13(65) \\
0(0)\end{array}$ & 19.155 & $<0.001 * *$ \\
\hline $\begin{array}{c}\text { Type of feeding: } \\
\text { NPO } \\
\text { Oral } \\
\text { Nasogastric tube }\end{array}$ & $\begin{array}{l}8(40) \\
4(20) \\
8(40)\end{array}$ & $\begin{array}{c}3(15) \\
7(35) \\
10(50)\end{array}$ & 3.313 & 0.23 \\
\hline
\end{tabular}

Table (3): Comparison of the serum troponin levels of the study groups

\begin{tabular}{|c|c|c|c|c|}
\hline \multirow{2}{*}{ Parameter } & \multicolumn{2}{|c|}{ Groups } & \multicolumn{2}{c|}{ Test } \\
\cline { 2 - 4 } & Case group & Control group & t & p \\
\cline { 2 - 4 } & Mean \pm SD & Mean \pm SD & & \\
\hline Serum troponin $(\mathrm{pg} / \mathrm{ml})$ & $184.87 \pm 4.31$ & $\mathbf{8 8 . 8} \pm 4.92$ & 10.087 & $\mathbf{0 . 0 0 1 * *}$ \\
\hline
\end{tabular}


Table (4): Correlation between troponin, clinical data, and laboratory parameters of studied groups

\begin{tabular}{|l|c|c|c|c|}
\hline \multirow{2}{*}{} & \multicolumn{4}{|c|}{ Serum troponin } \\
\cline { 2 - 5 } & \multicolumn{2}{|c|}{ Case group } & \multicolumn{2}{c|}{ Control group } \\
\cline { 2 - 5 } & $\mathbf{r}$ & $\mathbf{p}$ & $\mathbf{r}$ & $\mathbf{p}$ \\
\hline Gestational age (week) & -0.587 & $0.006^{*}$ & 0.71 & $<0.001^{* *}$ \\
\hline Age $($ days) & 0.408 & 0.074 & 0.319 & 0.17 \\
\hline Length $(\mathrm{cm})$ & -0.594 & $0.006^{*}$ & 0.078 & 0.744 \\
\hline Weight $(\mathrm{kg})$ & 0.146 & 0.538 & 0.883 & $<0.001^{* *}$ \\
\hline Heart rate & 0.209 & 0.376 & 0.4 & 0.081 \\
\hline Respiratory rate & 0.811 & $<0.001^{* *}$ & 0.16 & 0.502 \\
\hline APGAR 1 & -0.675 & $<0.001^{* *}$ & -0.937 & $<0.001^{* *}$ \\
\hline APGAR 5 & -0.767 & $<0.001^{* *}$ & 0.168 & 0.48 \\
\hline Down score & -0.306 & 0.189 & 0.132 & 0.579 \\
\hline TLC $\left(10^{3} / \mathrm{mm}^{3}\right)$ & 0.67 & $<0.001^{* *}$ & -0.839 & $<0.001^{* *}$ \\
\hline Platelet count $\left.\left(10^{3} / \mathrm{mm}\right)^{3}\right)$ & 0.481 & $0.032^{*}$ & -0.422 & 0.064 \\
\hline Hemoglobin $(\mathrm{g} / \mathrm{dL})$ & 0.43 & 0.058 & 0.758 & $<0.001^{* *}$ \\
\hline D. bilirubin $(\mathrm{mg} / \mathrm{dL})$ & 0.785 & $<0.001^{* *}$ & 0.269 & 0.251 \\
\hline Indirect bilirubin $(\mathrm{mg} / \mathrm{dL})$ & 0.428 & 0.06 & 0 & $>0.999$ \\
\hline Serum creatinine $(\mathrm{mg} / \mathrm{dL})$ & 0.425 & 0.062 & 0.14 & 0.555 \\
\hline Serum BUN $(\mathrm{mg} / \mathrm{dL})$ & 0.567 & $0.009^{*}$ & 0.523 & $0.018^{*}$ \\
\hline ALT (iu/L) & 0.548 & $0.012^{*}$ & 0.537 & $0.015^{*}$ \\
\hline AST & 0.673 & $<0.001^{* *}$ & -0.544 & $0.013^{*}$ \\
\hline CRP (mg/L) & 0.747 & $<0.001^{* *}$ & -0.592 & $0.006^{*}$ \\
\hline Serum sodium $(\mathrm{mEq} / \mathrm{dL})$ & 0.551 & $0.012^{*}$ & 0.581 & $<0.001^{* *}$ \\
\hline Serum potassium (mg/dL) & 0.473 & $0.035^{*}$ & 0.766 & $<0.001^{* *}$ \\
\hline
\end{tabular}

Table (5): Correlation between troponin and ECHO parameters

\begin{tabular}{|l|c|c|}
\hline \multirow{2}{*}{} & \multicolumn{2}{|c|}{ Case group } \\
\cline { 2 - 3 } & r & p \\
\hline LVEDD $(\mathrm{mm})$ & 0.569 & $0.021^{*}$ \\
\hline LVESD $(\mathrm{mm})$ & 0.25 & $0.087^{*}$ \\
\hline IVSSD $(\mathrm{mm})$ & 0.263 & 0.262 \\
\hline PWT $(\mathrm{mm})$ & 0.656 & $0.024^{*}$ \\
\hline IVS $(\mathrm{mm})$ & 0.169 & $0.007^{*}$ \\
\hline LA $(\mathrm{mm})$ & 0.253 & 0.281 \\
\hline Aorta(mm) & 0.011 & $0.064^{*}$ \\
\hline Ejection fraction $(\%)$ & 0.28 & $0.033^{*}$ \\
\hline Fraction shortening $(\%)$ & 0.66 & $0.022^{*}$ \\
\hline
\end{tabular}

Table (6) Performance of serum troponin in diagnosis of respiratory distress syndrome among the studied patients

\begin{tabular}{|c|c|c|c|c|c|c|c|}
\hline Cutoff & AUC & Sensitivity & Specificity & PPV & NPV & Accuracy & p \\
\hline$\geq \mathbf{9 3 . 5} \mathbf{~ n g} / \mathbf{m L}$ & $\mathbf{1}$ & $\mathbf{1 0 0 \%}$ & $\mathbf{8 0 \%}$ & $\mathbf{8 3 . 3 \%}$ & $\mathbf{1 0 0 \%}$ & $\mathbf{9 0 \%}$ & $<0.001 * *$ \\
\hline
\end{tabular}

$* * \mathrm{p} \leq 0.001$ is statistically highly significant AUC area under curve PPV positive predictive value NPV negative predictive value 


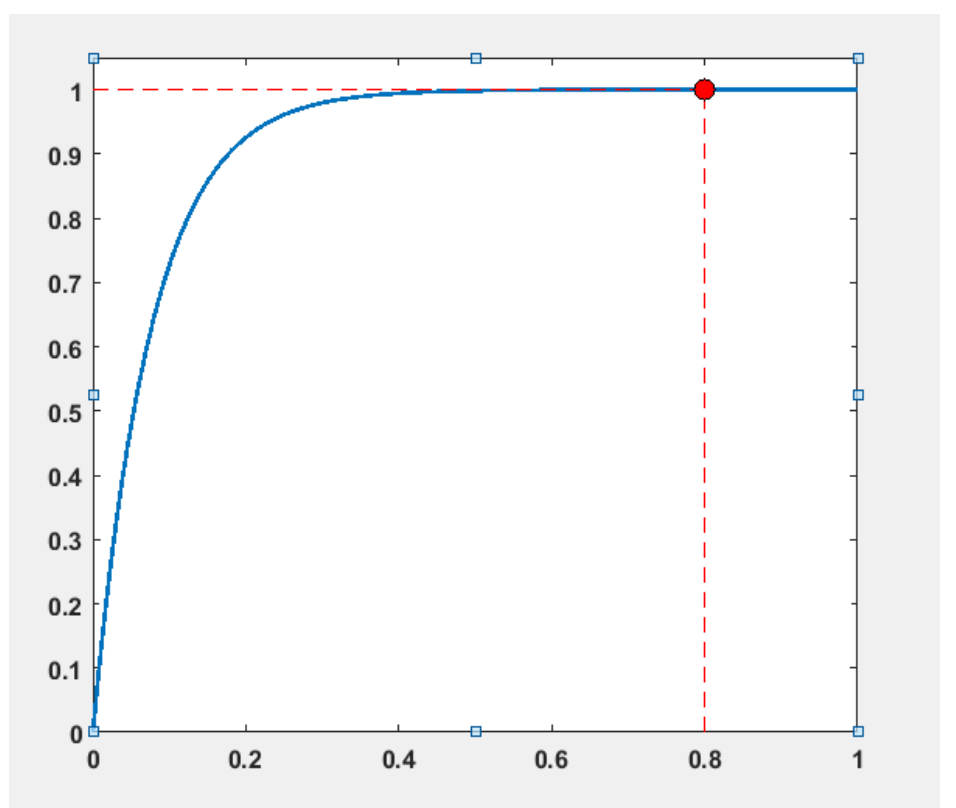

Figure (1): ROC curve showing performance of serum troponin in diagnosis of respiratory distress syndrome among the studied patients

\section{Discussion:}

A growing number of clinical trials are using cardiac biomarkers as indicators of myocardial strain. These findings may also help guide treatment and enhance outcomes. It is possible that they could be used to diagnose and treat infant diseases complicated by circulatory compromise ${ }^{(7)}$.

In our study, regarding demographic data between both groups, in the case group had done on 20 infants ( 8 males $40 \%, 12$ females $60 \%$ ) with mean age $2.9 \pm 064$, while the control group had done on 20 infants (11 males, 9 females) with mean age $3.35 \pm 049$ as in the order of birth.

On the other side, Tarkowska and Wanda ${ }^{(8)}$ his study on 80 infants with case group 50 infants (30male $60 \%, 20$ female $40 \%)$ and control 30(15 male 50\%,15 female $50 \%$ ). Our results were supported by Tarkowska and Wanda ${ }^{(8)}$ study researchers who found no statistically significant demographic differences between the groups analyzed.

In our study, regarding serum troponin, statistically significant differences were identified in serum troponin among the two study populations with mean \pm SD $184.87 \pm 42.31$ in the case group (it was significantly higher among the case group). And our results were supported by Tarkowaska and Wanda ${ }^{(8)}$ results who found that CTnT was useful as an early marker for respiratory distress syndrome in the neonate as case group with mean \pm SD $190.80 \pm 45.35$ among sick neonates, and also supported by Clark $\boldsymbol{e t}$ al. ${ }^{(\mathbf{1})}$ study with mean \pm SD $185.52 \pm 50.25$.these studies supported our results that CTnT was useful as an early indicator of respiratory distress syndrome, and it was found to be statistically significant in the case group compared to the control group.

In our study, regarding clinical data and grades of respiratory distress in case group with RDIII $60 \%$ and RDIV $40 \%$ presented with a murmur in $100 \%$ and cyanosis peripherally in $60 \%$ and centrally $40 \%$, in these sick infants, there were NPO in $40 \%$, oral feeding in $20 \%$ and nasogastric tube in $40 \%$. There was a significant difference in cyanosis between the two groups, but no significant difference in distress grades III, IV, or feeding type between the two groups.

On the other side Our results were not compatible with Clark et al. (1) (RD III 70\%, RD IV 30\%, peripheral cynosis65\% central 35\%) and EL-Khuffash et al. (9) (RD 80\%, RD IV 20\%, peripheral cyanosis $75 \%$ central cyanosis 25\%)and Noori and Seri ${ }^{(10)}$ (RDIII 80\%, RD IV 20\%, peripheral cyanosis $90 \%$, central cyanosis 10\%) their results showed the significant difference in cTnT between both groups regarding RDS and its grades and cyanosis in which CTnT was higher in the case group than control one with no congenital disorders.

The findings of the present study were also in keeping with previous studies made by Awany et al. ${ }^{(7)}$ who found an increased level of cTnT in infants on inotropes, it reaches statistical significance. infants with respiratory distress syndrome who required pressor support had higher blood levels of cTnT compared to those without the need for pressors. Awany et al. ${ }^{(7)}$ also found a statistical difference between infants on inotropes and those not in inotropes and previous studies which have shown cardiac dysfunction in very-low-birth-weight infants and infants with Perinatal asphyxia and RDS.

Studies done by EL-Khuffashet al. (9) and Awada et al. ${ }^{(11)}$, found an increased level of cTnT in infants on inotropes, although it reached statistical significance with oxygen requirement or the use of inotropic support.

In our study, regarding the correlation between CTnT and the clinical data, we found: (1) among the case group, the -ve statistically significant correlation between serum CTnT and gestational age (_0.587), length (_0.594) APGAR 1(_0.675) and APGAR 5 
(_0.767) and +ve statistically correlation between serum CTnT and respiratory rate (0.811). (2) Among the control group, the -ve correlation between serum CTnT and APGAR 1(_0.937) and +ve correlation between serum CTnT and gestational age (0.71) and weight $(0.883)$.

These results are supported and compatible with Clark et al. ${ }^{(1)}$ study who found the _ve statistically significant correlation between serum CTnT and gestational age (_0.677), length (_0.744) APGAR 1(_0.658), and APGAR 5 (_0.887) and +ve statistically correlation between serum CTnT and respiratory rate (0.711) among his case group. So, there was confirmation in this correlation enhanced by both studies.

On the other hand, in our study, we studied the correlation between serum $\mathrm{CTnT}$ and laboratory parameters among case group and we found, +ve correlation between CTnT and TLC (0.67), platelets account (0.481), direct bilirubin (0.785), blood urea, nitrogen (0.567), ALT (0,548),AST(0.673), $\mathrm{CRP}(0.747)$, serum $\mathrm{Na}(0.551)$ and $\mathrm{K}(0.473)$. So, there was a statistically significant correlation between serum CTnT and these parameters in the case group, these results were supported and compatible by Awany et al. ${ }^{(7)}$ study who found the correlation between CTnT and TLC (0.75), platelets account (0.580), direct bilirubin, blood urea, nitrogen, ALT, AST, CRP, serum $\mathrm{Na}$, and $\mathrm{K}$.

On the other side, Tarkowaska and Wanda ${ }^{(8)}$ study was noncompatible with my study and Awany $\boldsymbol{e t}$ al. ${ }^{(7)}$ study as they found no correlation between CTnT and lab parameters TLC, platelets account, direct bilirubin, blood urea, and nitrogen, ALT, AST, CRP, serum Na and $\mathrm{K}(0.085)$, with no significant importance in both groups.

Regarding ECHO parameters, in our study, among the case group we found that +ve correlation between CTnT and parameters because dependent on $\mathrm{ECHO}$ investigation to evaluate cardiac dysfunction in a preterm infant with RDS, mostly on CTnT that rises mostly in the third day in infant despite normal ECHO with no congenital anomalies in the heart. in my study. In case group,+ve significant difference in parameters LVEDD (0.569), LVESD (0.25), PWT (0.656)IVS $(0.169)$, aorta $(0.11)$ ejection fraction $(0.28)$ fraction shortening (0.66) these results were supported and compatible with Clark et al. (1) LVEDD (0.559), LVESD (0.35), PWT (0.666)IVS (0.269), aorta (0.12) ejection fraction (0.30) fraction shortening (0.65), ELKhuffash (9) LVEDD, LVESD, PWT, IVS, aorta ejection fraction, fraction shortening, so these studies and our study approached that there was +ve correlation between CTnT and ECHO parameters.

We observe in our results, the performance of serum troponin in diagnosing RDS among studied infants, cutoff $\geq 93.5 \mathrm{ng} / \mathrm{mL}$, with sensitivity $100 \%$, specificity $80 \%$, PPV $83.3 \%$, NPV 100\%, accuracy
90\% .these data are supported and corroborated with Tarkowaska and Wanda ${ }^{(8)}$ study and Awada et al. ${ }^{(11)}$ study.

\section{CONCLUSION}

Cardiac troponin is higher in a sick preterm infant with RDS than healthy neonates. Cardiac dysfunction is a common sequence complication of respiratory distress syndrome. Cardiac troponin $\mathrm{T}$ can be a marker for the detection of cardiac dysfunction in sick neonates especially in the centers without in situ echocardiography. We recommend using portable echocardiography in NICU for assessment of hemodynamic and cardiac function in neonates with RDS for early control and treatment.

\section{Financial support and sponsorship: Nil. Conflict of interest: Nil.}

\section{REFERENCES}

1. Clark A, Danial C, Christinal K et al. (2017): Biomarkers level in cardiac dysfunction. cardiac dysfunction in neonate and pediatric. Journal American Coll Cardiology, 5: 400-450.

2. Young S (2020): Neonatal respiratory distress: recent progress in understanding pathogenesis and treatment outcomes, algorithm treatment with surfactant. Korean Journal of Pediatrics, 5: 310-350.

3. Huggon A, Chambers J, Tutt $P$ et al. (2001): Biochemical markers in the management of suspected acute myocardial infarction in the emergency department. Emergency Medicine Journal, 18:15-19

4. Thygesen D, Takeuchi K, Saitoh L (2019): Elevated cardiac troponin concentration and correlation with cardiac dysfunction. Journal of Pediatric and Neonatal Care, 19: 1-7.

5. Nikhilesh K, Noori S, Seri D et al. (2015): Cardiac troponin as biomarkers in RDS in preterm infants. Journal of Interventional Cardiology, 6: 150-170.

6. Dong P, Speer G, El khuffash A (2018): Common respiratory conditions of the newborn. Journal of Interventional Cardiology, 3: 100-115.

7. Awany E, David S, Bader F et al. (2016): preterm infant with RDS, cardiac troponin $\mathrm{T}$ level with sepsis and its correlation with morbidity and mortality. Jornal of Pediatric and Neonate, 15: 50-59.

8. Tarkowaska J, Wanda L (2017): Cardiac Troponin T as a Useful Early Marker of Cardiac Dysfunction in Neonates with Respiratory Distress, perinatal asphyxia. Jornal of Pediatric and Neonate, 11: 1-4.

9. El khuffash A (2018): The sustained rise of cardiac troponin from damaged cardiac tissue and cardiac troponin in cardiac dysfunction. Journal American Coll Cardiology, 5: 250-270.

10. Noori D, Seri G (2015): Myocardial Injury Biomarkers in Newborns with Congenital Heart Disease. Arch Dis Child Fetal Neonatal, 5: 150-170.

11. Awada B, Al Biltagi J, Bader D et al. (2017): Cardiovascular disease and diagnosis. Journal of Pediatric and Neonatal Care, 2: 170-179. 